\title{
Five Theses on the Future of Special Collections
}

I WAS PLEASED TO be asked by Shannon Supple and Nina Schneider, co-chairs of the 2012 RBMS preconference, to reflect on the themes of the conference in these pages. The presentations were engrossing and provocative, and I hope here to offer some equally provocative thoughts in response as my contribution to the ongoing discussion about the peril and promise-mostly, I firmly believe, the latter-that the future holds for our profession.

The future of special collections is distribution. It hardly needs to be said that digitization, and the ability to share digitized materials widely, is enacting a wholesale transformation on the work of special collections librarianship. It's easy, in the quiet of the reading room, to imagine that special collections is somewhat immune from the challenges facing other areas of the profession; but, even if that were something to be hoped for, it would be a false hope. Special collections will increasingly serve an audience that does not, and in many cases need not, cross its threshold. Changes in our base of users will necessitate changes in our methods of assisting those users, as well as changes in the kinds of materials we acquire and prioritize for conservation and digitization.

Frustratingly, there is still far too much friction in the process of matching users with the materials they need. The content we make available online is too often trapped in institutional silos, invisible to the researcher (and let he who is without sin cast the first stone here) who relies on Google to begin the search process. It is clearly unrealistic to expect anyone to check library catalog after library catalog in the vain hope that somebody, somewhere has digitized one particular book. One possible way forward lies in the development of more multi-institutional repositories such as Europeana, ${ }^{1}$ which brings together the digital collections of more than a thousand institutions across Europe in a single searchable portal. We ought also to be constantly on the lookout for new venues through which to share our collections, new opportunities to meet potential users on their own turf, and ways to introduce them to what we have to offer. We can no longer, if we ever could, afford to wait for users to come to us.

1. Available online at www.europeana.eu/portal/ [accessed 18 February 2013]. 
The future of special collections is openness. We are not the creators of our collections; we are their stewards. They were entrusted to us to preserve them, certainly, but preservation without use is an empty victory. It ought to be our primary purpose at all times to minimize barriers to use, so it is all the more shameful when we interpose such barriers ourselves, not out of concern for the health of the collections, but out of the misguided belief that we are entitled to control, even to monetize, their use. When we claim copyright over our digital collections, or impose permission fees or licensing terms on users, we are arguably misrepresenting the law, and certainly violating one of the central ethical tenets of the profession: to promote the free dissemination of information. And, when those conditions are demanded by donors, we ought to consider whether we can accept collections under such circumstances.

No one reading this can be unaware of the plundering of the public domain that has occurred over the last several decades at the behest of corporations determined to wring every last dollar out of their intellectual property. Continual extensions of copyright terms have impeded scholarship and caused paralysis in our profession, locking up the overwhelming majority of out-of-print books that have no chance of further commercial exploitation for the sake of a privileged few. Through an understandable excess of caution, the tendency at most institutions is to retreat from the fuzzy edges of the rights we do have, always wondering, "What if somebody complains? What if somebody sues?" The potentially devastating consequences are often enough to scuttle any expeditions into the gray areas of the law.

Why, then, would we ever add to that morass of anxiety and constraint by imposing use restrictions of our own? Why would we participate in the chipping away of the public domain by asserting copyright over a picture of a centuries-old book? Why would we create an additional barrier to open scholarship by claiming the right to refuse permission to publish such an image, or to charge a fee for such permission? Some might argue that the question of whether we are legally entitled to insist on this level of control is still unsettled (at least in the United States). What is not open to question, however, is that to do so runs counter to our professional responsibility to maximize access, and even simple self-interest: the easier we make it to use our collections, the more we visibly demonstrate their value.

It is hard not to sympathize with institutions that have depended on such revenue as an important part of the budget, one not easily replaced in the current economic climate. I believe, however, that the commitment to openness must take precedence to the greatest extent possible. It is encouraging to see a number of institutions moving in this direction; for example, the recent decision by the British Library to label as public domain the images in its Catalogue of Illuminated 
Manuscripts. ${ }^{2}$ A particularly inspiring leader in this area is Yale University, which in 2011 announced that it would make digital images of its collections available under a blanket open access policy. ${ }^{3}$

Furthermore, there is immense potential for collaboration between the emerging field of university-centered open access publishing and special collections-particularly when such initiatives are based within the library system. At Amherst College, which recently announced the launch of an open access digital press focused on the liberal arts and housed at the Frost Library, ${ }^{4}$ the Archives and Special Collections division likewise made the decision to digitize its Emily Dickinson manuscripts and post them online with an unambiguous endorsement of openness:

Amherst College can neither grant nor deny permission to publish or quote from materials in its collections. Neither titles nor facts can be copyrighted; therefore, permission is not required to cite a collection as a source or to use facts from it. ${ }^{5}$

The future of special collections is disintermediation. Committing to openness necessarily entails what may instinctually feel like a loss of control. As our collections become increasingly shareable, they become increasingly unmoored from the organizational and interpretive contexts we have carefully constructed for them. These contexts have great value, constituting one of the most important parts of our work as special collections librarians. It would be more productive, however, not to mourn our loss of control, but to celebrate the empowerment of users.

In her talk "Mimicry or Invention” Joanna Drucker rightly pointed out that

No text was ever produced in isolation. All texts are dialogs. All scholarship is a work of community practice, and that what a book does is to stop motion for a moment and take a snapshot of those conversations, while recording what the poet Steve McCaffery says is "the centrifugal and centripetal forces of interconnected discourses within its pages."6

2. Available online at www.bl.uk/catalogues/illuminatedmanuscripts/reuse.asp [accessed 18 February 2013].

3. Available online at http://news.yale.edu/2011/05/10/digital-images-yale-s-vast-cultural-collections-now-available-free [accessed 18 February 2013].

4. Available online at https:/ / www.amherst.edu/aboutamherst/news/news_releases/2012/12/ node/ 445320 [accessed 18 February 2013].

5. Available online at http://consecratedeminence.wordpress.com/2013/01/04/digital-dickinson/ [accessed 18 February 2013].

6. Johanna Drucker, "Mimickry or Invention" (time 18:30), available online at www.rbms.info/ conferences/preconfdocs/2012/Talks/2012_plenary_closing.mp3 [accessed 18 February 2013]. 
Rather than focusing our efforts primarily on reproducing in an online space the experience of reading a book in a physical one - the mimicry of Drucker's title-we have an unprecedented opportunity to reignite the conversations and reunite the communities represented by the texts in our collections.

A number of special collections-driven projects are demonstrating the tremendous potential for crowd-sourcing to enable a vast new audience to simultaneously derive value from our materials and add value to them in ways that go far beyond what has been heretofore possible. Fans of the New York Public Library's What's on the Menu project ${ }^{7}$ have added searchable transcriptions and prices for more than 15,000 menus in less than two years, labor freely donated out of an interest in the subject and a willingness to contribute. By participating in Flickr Commons, ${ }^{8}$ the Library of Congress and numerous other institutions have gained valuable context and metadata for their photographs by empowering users to share what they know, harnessing the power of a virtual army to enrich their collections to a degree far in excess of what they could hope to accomplish internally.

The future of special collections is transformation. We can't know what uses will be made of our collections once we put them in the world's hands, and indeed that is the brightest promise of the digital future. We will be constantly surprised by the uses made of our collections in ways we could have never imagined and on scales we could never have accomplished on our own. It would be naïve to promise that we won't occasionally be appalled as well, but it's a small price to pay.

We are privileged to be working at the dawn of an era in which special collections will become the raw materials upon which the creative energies of the world can be exercised. Once freed from the confines of the reading room and transmuted into malleable digital form, we can expect an explosion of innovative uses by nontraditional users. Indeed, that process is already beginning. As Jon Voss demonstrated in his plenary talk, Historypin ${ }^{9}$ embeds historic photos into the contemporary landscape at the location at which they were taken, giving them a richer context and relevance. Of course, photographs aren't the only type of material that can benefit from being thus situated, and one hopes that Historypin will follow up on its stated goal of creating mechanisms for other kinds of primary sources.

The future of special collections is advocacy. When discussing the value and importance of special collections, we frequently talk of the ineffable experience of coming face to face with the artifacts of our history. The time has come, if you will

7. Available online at http://menus.nypl.org/ [accessed 18 February 2013].

8. Available online at www.flickr.com/commons [accessed 18 February 2013].

9. Available online at www.historypin.com [accessed 18 February 2013]. 
forgive me, to eff it. In a time of hard choices, we will be increasingly called upon to defend the relevance of our work and the resources it demands. Special collections cannot survive merely as a prestigious ornament to the university; we will need to articulate the centrality of our collections to the university's mission.

Special collections exists to serve the needs of researchers. The way it meets those needs is rarely self-evident; it must be constantly demonstrated. Research in primary sources is a habit that must be cultivated, all the more so in an era of convenient alternatives. Students who hone their research skills as undergraduates and graduates from the comfort of a dorm room are unlikely to decide on their own initiative to explore the mysteries of the special collections library as faculty. They must be reached early and often with a message that mixes the genuine pleasure and wonder of our collections with a much more practical one: our library and the people who work there can make your research easier and its products better. Only the most motivated students will cross our thresholds on their own. Special collections is often an intimidating place, with elaborate rules and extra hurdles to access. That makes it crucial to reach out and demystify special collections, to convey the message: "Please touch. This is here for you. You are special enough for special collections."

The recent Ithaka S+R report "Supporting the Changing Research Practices of Historians" ${ }^{\prime 10}$ is disheartening in its depiction of scholars who see little role for librarians as partners in their work, a view that rests on the presumption that the practiced researcher has little need of assistance, particularly in the digital age, from a librarian lacking a detailed knowledge of a particular subject specialty. While it is true that we will rarely know as much about any given subject as the scholars we work with, we are each of us experts in the work of information discovery and in our own collections. We have much to offer, but it is clear that assertive salesmanship and repeated demonstration of that value are crucial to our future. Special collections must create satisfied users who can be vocal advocates for our importance to survive in times of budgetary stress.

We would do well to reflect on Michael Suarez's provocative questions about the ways in which we communicate our purpose and value without speaking:

How is the way that your collections are mediated telling those who are in contact with them about their treasureful-ness? About the power of materiality that's ritually taken out and placed in someone's hands (or

10. Jennifer Rutner and Roger C. Schonfeld, "Supporting the Changing Research Practices of Historians," available online at www.sr.ithaka.org/research-publications/supporting-changing-researchpractices-historians [accessed 18 February 2013]. 
not)? What would you encase in jewels and gold? ... If we don't understand our institutions as places of pilgrimage, as places of material embodiments that have profound effects on community, identity, and the expression of humanities, then we do not understand the vocation of the librarian ... a high and noble vocation in which we are the custodians of a materiality that is absolutely intrinsic to the identity of our civilization. ${ }^{11}$

This is a time in which the relevance and mission of the library is under threat. The good news is, as Bethany Nowviskie reminded us in surely the most memorable words of the conference, "Existential threats don't scare us. We're librarians." ${ }^{12}$ It was impossible to leave the conference without feeling that the profession has deep reserves of innovation and drive to meet these challenges with creative thinking, while continuing to preserve and promote its core values.

11. Michael F. Suarez, S.J., "Book: Object-Futures of the Special Collections Library (time 59:03), available online at www.rbms.info/conferences/preconfdocs/2012/Talks/2012_plenary_closing.mp3 [accessed 18 February 2013].

12. Available online at http://nowviskie.org/2012/reality-bytes/ [accessed 18 February 2013].

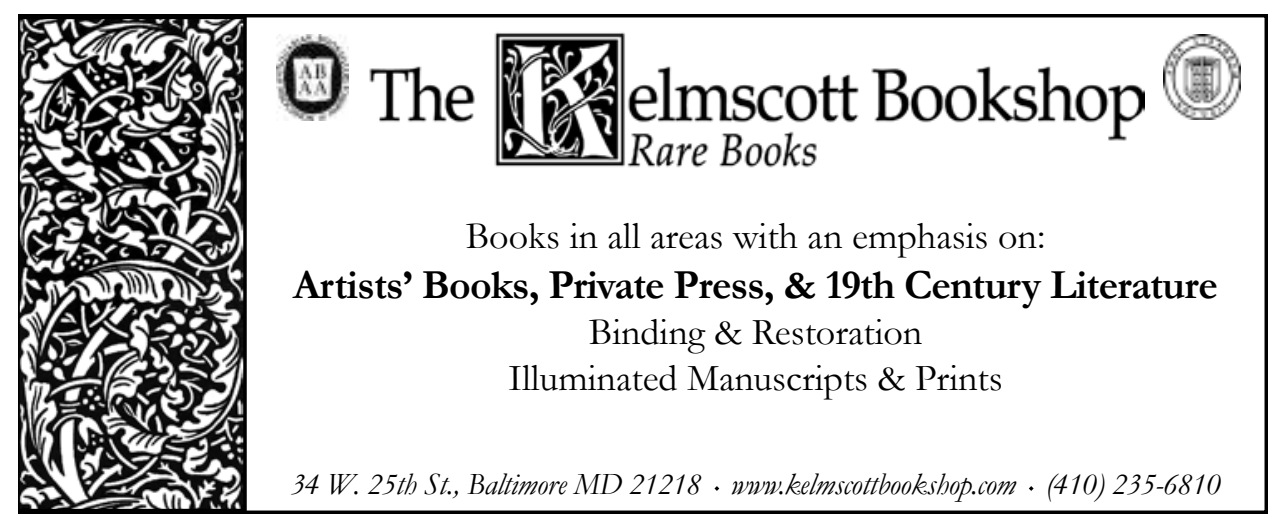

